\title{
Calorie menu labeling on quick-service restaurant menus: an updated systematic review of the literature
}

\author{
Jonas J Swartz ${ }^{1 *}$, Danielle Braxton ${ }^{2}$ and Anthony J Viera ${ }^{1,3}$
}

\begin{abstract}
Nutrition labels are one strategy being used to combat the increasing prevalence of overweight and obesity in the United States. The Patient Protection and Affordable Care Act of 2010 mandates that calorie labels be added to menu boards of chain restaurants with 20 or more locations. This systematic review includes seven studies published since the last review on the topic in 2008. Authors searched for peer-reviewed studies using PUBMED and Google Scholar. Included studies used an experimental or quasi-experimental design comparing a calorielabeled menu with a no-calorie menu and were conducted in laboratories, college cafeterias, and fast food restaurants. Two of the included studies were judged to be of good quality, and five of were judged to be of fair quality. Observational studies conducted in cities after implementation of calorie labeling were imprecise in their measure of the isolated effects of calorie labels. Experimental studies conducted in laboratory settings were difficult to generalize to real world behavior. Only two of the seven studies reported a statistically significant reduction in calories purchased among consumers using calorie-labeled menus. The current evidence suggests that calorie labeling does not have the intended effect of decreasing calorie purchasing or consumption.
\end{abstract}

Keywords: Calorie label, menu label, nutrition information, restaurant label, Patient Protection and Affordable Care Act, obesity, food away from home, fast food

\section{Introduction}

As part of the Patient Protection and Affordable Care Act of 2010, lawmakers passed a requirement that all chain restaurants with 20 or more locations include calorie information on all menus. If enacted, the policy will require these restaurants to list at the very least the calorie information in the foods and beverages they serve. This new legislation builds upon efforts already underway in some states to provide consumers with more information about the foods they purchase away from the home [1].

Menu labeling is one of many policy approaches that has been proposed to address the increasing prevalence of overweight and obesity in the United States $[2,3]$. In particular, researchers and policymakers have begun to focus on how the increasing reliance on food away from

\footnotetext{
* Correspondence: jonas_swartz@med.unc.edu

'Public Health Leadership Program, Gillings School of Global Public Health,

University of North Carolina at Chapel Hill, Chapel Hill, NC, USA Full list of author information is available at the end of the article
}

home in the US diet $[4,5]$ may be contributing to poor health $[6,7]$. Food away from home now accounts for over $30 \%$ of daily caloric intake and $50 \%$ of yearly food spending [4-6]. This trend is concerning because foods consumed away from home typically have more calories, fat and sodium than foods prepared in the home [4]. Frequent consumption of food away from home has also been linked to higher rates of overweight and obesity $[8,9]$.

In an effort to address the role of food away from home in the overweight and obesity epidemic, several states, cities and counties have passed menu labeling laws starting with New York City in 2006. The New York City law required restaurants with 15 or more locations to list calorie information for each item on the menu in a prominent location both on menu boards and menus and began enforcement in 2008. Shortly thereafter, in 2010, Congress passed the Patient Protection and Affordable Care Act which included a national
C Biomed Central 
menu labeling law for all restaurants with 20 or more locations $[1,10]$.

Though momentum has gathered behind menu labeling policies as a tool for combatting overweight and obesity, evidence to support its efficacy is less robust. In a 2008 review, Harnack and French were able to identify only six studies that tested the effects of calorie labeling on consumer choice [5]. They concluded that from the current evidence, the effects of calorie labeling appeared to be weak or inconsistent [5]. However, they also noted major methodological flaws in each of the studies [5].

In this systematic review, we update Harnack and French's findings with more recent evidence. The purpose of this paper is to use current literature to answer the question of whether calorie labeling on menus at restaurants and cafeterias has an effect on consumer purchasing and eating behaviors.

\section{Methods}

\section{Search strategy}

The most recent review of the literature was published in 2008 and included articles published through 2006. In the current search, conducted in August 2011, we sought studies with publication dates from 2006-August 2011. We used PUBMED and Google Scholar World Wide Web search engines to identify relevant studies. Initial PUBMED searches with MeSH terms including "food labeling", "fast foods" and "choice behavior" yielded few results. We therefore broadened our search to include the following keywords: "calorie labeling", "menu labeling" and "point-of-purchase labeling". We supplemented our findings with hand searches from the reference lists of articles and reviews [7,11-15].

\section{Article selection}

To be included, studies must have used an experimental or quasi-experimental design comparing a calorielabeled menu with a no-calorie menu. This review includes studies conducted in laboratories, college cafeterias, and fast food restaurants. Only studies that measured purchasing behavior or consumption of ready-toeat meals were included. Our search was restricted to English-language in peer-reviewed publications.

\section{Data extraction}

One author (JS) extracted standardized information including study aims, study type, sample population, and outcomes in a spreadsheet to facilitate comparison and synthesis. The table also included information about methodological strengths and weaknesses of the studies.

\section{Quality assessment}

Quality was graded with the assistance of an instrument developed by the investigators based on standard critical appraisal criteria. The instrument required assessment of a variety of study procedures including study design, randomization, blinding, minimization of selection bias, minimization of measurement bias, and minimization of confounding bias. For each applicable variable, two authors (JS and AV) independently assessed each article and assigned scores of 2 for good, 1 for fair and 0 for poor. To achieve a quality rating of good, studies had to have an average score greater than or equal to 1.5 and could not receive scores of 0 for any individual variable. An average score less than or equal to 0.5 was considered to indicate a study with poor quality. Studies with scores in between were considered fair quality studies. We excluded the randomization category for observational studies. After independently scoring each article, the two raters conferred to discuss any discrepancy in overall quality rating.

\section{Results}

Search results

The initial search produced 164 citations on PUBMED. One author (JS) screened titles for relevance and further examined 32 abstracts. Eighteen articles underwent full text review, after which 12 articles were excluded. One article was included from a hand search. Seven articles met the inclusion and exclusion criteria described above (Figure 1).

\section{Study design}

Included articles reported on studies conducted in two different types of settings; five articles reported on natural experiments of calorie menu label implementation in real world settings [6,16-19] and two involved researcher manipulated variables in laboratory settings $[20,21]$ (Table 1).

\section{Study quality}

All studies included in this review had methodological shortcomings. Despite these limitations, two studies were judged by the two raters to be of good quality $[19,20]$ and five to be of fair quality $[6,16-18,21]$ (Table 2).

\section{The effect of calorie menu boards on calorie ordering and purchasing}

All seven studies compared calorie ordering and purchasing in two conditions: calorie label versus no calorie label. Two studies reported that calorie menu labels reduced the calories purchased [6,21], one reported significant reductions in calories purchased at some chains (but not others)[16], three reported no effect on calories purchased $[17,18,20]$ and one reported a slight increase in calories purchased [19].

Among the observational studies, Elbel et al. found that in New York City, purchasing behavior of children 


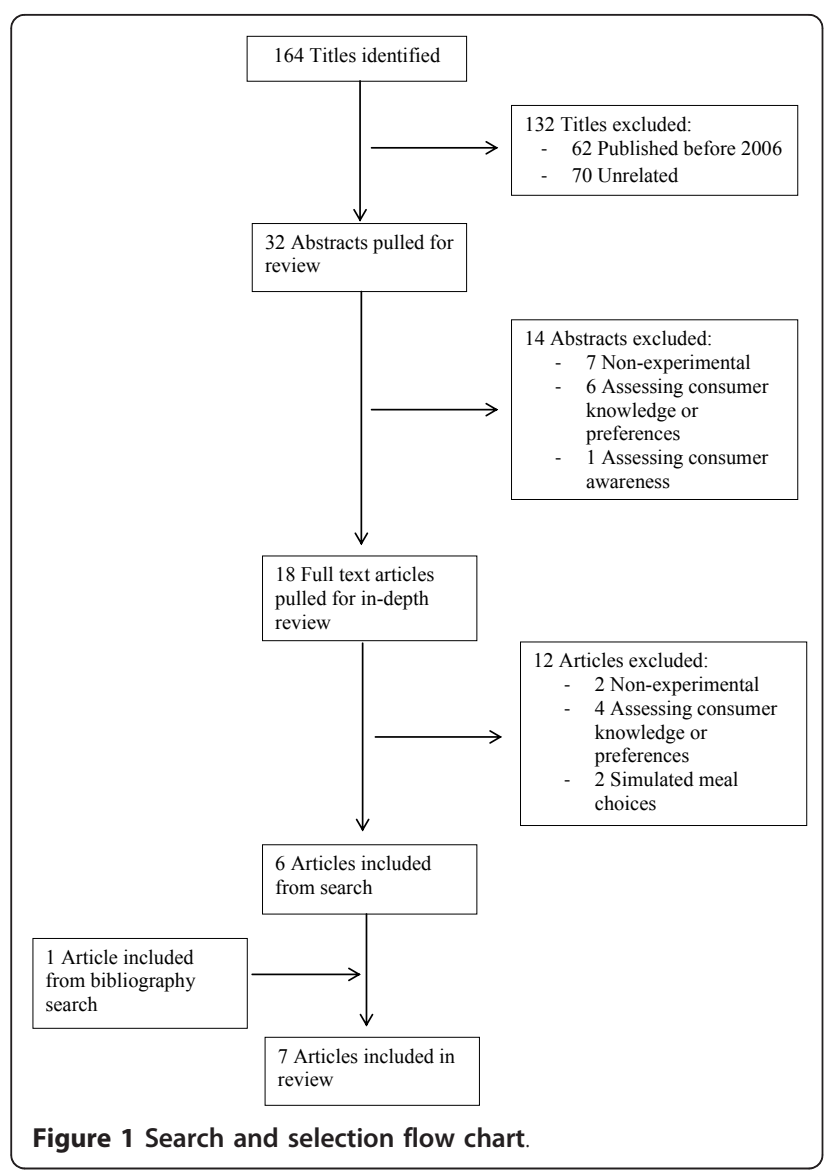

and adolescents did not differ before and after calorie labels were implemented on menu boards, with patrons purchasing a mean of 643 calories before labeling and 652 calories $(\mathrm{p}=0.82)$ after restaurants introduced menu labels [17]. The authors also observed a non-significant change in purchasing behavior over the same time period among children and adolescents in Newark, $\mathrm{NJ}$, where calorie labels were not introduced (611 vs. 673 calories, $p=0.37$ )[17]. A companion study of adults also showed a non-significant difference in New York City [18]. Adults purchased a regression-adjusted mean of 825 calories (95\% CI: 779-870) before calorie labeling and 846 calories (95\% CI: 758-889) after calorie labeling. There was also a non-significant trend among adults in Newark, NJ with 823 calories (95\% CI: 802-890) in the pre-labeling time period and 826 calories (95\% CI: 746906) in the post-labeling time period [18].

Also in New York City, Dumanovsky et al. collected survey and purchase data before calorie labeling implementation in 2007, and nine months after implementation in 2009. They collected data from the 11 largest fast food chains, and found no change in mean calories purchased overall between study periods in 2007 and 2009 (828 vs. 846 calories, $\mathrm{P}=0.22)[16]$. When examining data for each chain individually, they found a reduction in mean calories purchased for three chains (McDonald's 829 vs. 785 calories, $\mathrm{P}=0.02$; Au Bon Pain 555 vs. 475 calories, $\mathrm{P}<0.001$; KFC 927 vs. 868 calories, $\mathrm{P}<0.01$ ), no significant difference for 7 chains (Burger King, Wendy's, Popeye's, Domino's, Pizza Hut, Papa John's, Taco Bell), and an increase for one chain (Subway 749 vs. $882, \mathrm{P}<0.001)[16]$. The study did not include a control population.

Though it was a small change, Finkelstein et al. did observe a small, statistically significant (but we do not think clinically significant) increase in calories purchased per transaction after calorie labels were added to menus in King County, WA [19]. Patrons purchased 5.7 (p < $0.05)$ more calories after calorie labels were introduced on menu boards inside restaurants, and $2.9(\mathrm{p}<0.05)$ more calories after calorie labels were introduced on drive-thru menu boards. In the control county, they did not observe a significant trend. Moreover, a differencein-difference regression analysis found that calories per transaction were not reduced after the legislation [19].

In a study of entrée purchasing in a college dining hall, Chu et al. reported a significant but modest decrease in calories per entrée sold during the two weeks that calorie labels were posted on menu boards (treatment)[6]. They calculated average calories per sale using sales data furnished by the cafeteria. In the two weeks before posting calorie information (pretreatment), the average energy content was 646.5 calories per entrée. This average dropped 12.4 calories per entrée sold on the first day of calorie posting $(p=0.007)$ and remained lower throughout the treatment period. Though statistically significant, an average reduction of 12.4 calories may not be clinically significant.

In contrast to studies utilizing only purchasing behavior, the two experimental studies conducted in laboratory settings allowed researchers to measure both calories ordered and calories consumed (discussed below)[20,21]. Harnack et al. found no significant difference in calories ordered among four menu labeling conditions manipulating availability of calorie labels and value pricing (calorie labels + value pricing 874 , calorie labels without value pricing 842 , no calorie labels + no value pricing 882 , and no calorie labels + value pricing (control) 828 calories, $\mathrm{p}=0.62$ )[20].

Roberto et al. tested three types of menus: one had no calorie labels (no label), one had calorie labels (calorie), and one had calorie labels and a statement that the recommended daily caloric intake was 2000 calories (calorie + information)[21]. They found that menu type had a statistically significant effect on calorie ordering ( $p$ $=0.04$ ). Significant differences were found between the no label and calorie labeled menus (no label 2189, calorie 1862 calories, $\mathrm{p}=0.03$ ), and also a significant 
Table 1 Characteristics of included studies

\begin{tabular}{|c|c|c|c|c|c|}
\hline Reference & $\begin{array}{l}\text { Design and } \\
\text { Presence of } \\
\text { Comparison } \\
\text { Group } \\
\end{array}$ & Intervention/Measures & Setting & $\begin{array}{l}\text { Number of } \\
\text { Subjects/ } \\
\text { Restaurants }\end{array}$ & Result \\
\hline \multicolumn{6}{|l|}{$\begin{array}{l}\text { Real world } \\
\text { setting }\end{array}$} \\
\hline $\begin{array}{l}\text { Elbel et al. } \\
\text { (2011) [17] }\end{array}$ & $\begin{array}{l}\text { Natural } \\
\text { experiment, pre/ } \\
\text { post intervention } \\
\text { comparison and } \\
\text { with matched } \\
\text { community }\end{array}$ & $\begin{array}{l}\text { Calorie labels added to chain } \\
\text { restaurant labels in New York } \\
\text { City. Survey administered } \\
\text { outside fast food restaurants. }\end{array}$ & $\begin{array}{l}\text { New York City and } \\
\text { Newark, NJ (as } \\
\text { comparator). Fast } \\
\text { food restaurants in } \\
\text { low-income } \\
\text { neighborhoods }\end{array}$ & $\begin{array}{l}349 \text { children and } \\
\text { adolescents }\end{array}$ & $\begin{array}{l}\text { Mean calories purchased in NYC } \\
\text { pre and post labeling } 643 \vee 652 \\
\begin{array}{c}(p=0.82) \text {, Newark } 611 \vee 673(p \\
=0.37) .\end{array}\end{array}$ \\
\hline $\begin{array}{l}\text { Elbel et al. } \\
\text { (2009) [18] }\end{array}$ & $\begin{array}{l}\text { Natural } \\
\text { experiment, pre/ } \\
\text { post intervention } \\
\text { comparison and } \\
\text { with matched } \\
\text { community }\end{array}$ & $\begin{array}{l}\text { Calorie labels added to chain } \\
\text { restaurant labels in New York } \\
\text { City. Survey administered } \\
\text { outside fast food restaurants. }\end{array}$ & $\begin{array}{l}\text { New York City and } \\
\text { Newark, NJ (as } \\
\text { comparator). Fast } \\
\text { food restaurants in } \\
\text { low-income } \\
\text { neighborhoods }\end{array}$ & $\begin{array}{l}1156 \text { adults over } \\
18\end{array}$ & $\begin{array}{c}\text { Regression-Adjusted nutrient } \\
\text { content in NYC and Newark } \\
\text { before and after with } 95 \% \mathrm{Cl} \text {. } \\
\text { NYC: } 825(779,870) \text { post } 846 \\
(758,889) \text {. Newark } 823(802,890) \\
\text { post } 826(746,906) .\end{array}$ \\
\hline $\begin{array}{l}\text { Finkelstein et } \\
\text { al. (2011) [19] }\end{array}$ & $\begin{array}{c}\text { Natural } \\
\text { experiment, pre/ } \\
\text { post intervention } \\
\text { comparison with } \\
\text { matched } \\
\text { communities }\end{array}$ & $\begin{array}{l}\text { Calorie labels added to chain } \\
\text { restaurant labels in King County, } \\
\text { WA, then drive-thru lanes. Total } \\
\text { monthly transactions and } \\
\text { calories per transaction. }\end{array}$ & $\begin{array}{l}\text { King County, WA and } \\
\text { several stores from } \\
\text { surrounding area }\end{array}$ & $\begin{array}{l}21 \text { randomly } \\
\text { selected Taco } \\
\text { Time locations } \\
\text { and } 7 \text { locations } \\
\text { outside King } \\
\text { County }\end{array}$ & $\begin{array}{c}\text { Calories per transaction King } \\
\text { County pre-period: } 1,211 \vee \text { post- } \\
\text { period } 1: 1,217 \vee \text { post-period } 2 \text { : } \\
\text { 1,214. Calories per transaction } \\
\text { Control pre-period: } 1,391 \vee \text {. post- } \\
\text { period } 1: 1,392 \vee \text { post-period } 2 \text { : } \\
1,376 .\end{array}$ \\
\hline $\begin{array}{l}\text { Chu et al. } \\
\text { (2009) [6] }\end{array}$ & $\begin{array}{c}\text { Quasi- } \\
\text { experimental, } \\
\text { single group } \\
\text { interrupted time } \\
\text { series } \\
\end{array}$ & $\begin{array}{l}\text { Calorie labels added to entrees } \\
\text { in college dining hall. Used } \\
\text { electronic sales data to track } \\
\text { calories of entrees sold. }\end{array}$ & $\begin{array}{l}\text { Dining hall, Ohio } \\
\text { State University }\end{array}$ & NA & $\begin{array}{c}\text { Calories per entrée sold at pre } \\
645.5 \text {, First day of tx period }-12.4 \\
\text { ( } p=0.007) \text {, decreased of } 0.298 \\
\text { calories/day), post treatment } \\
\text { increases } 1.512 / \text { day }\end{array}$ \\
\hline $\begin{array}{l}\text { Dumanovsky } \\
\text { et al. (2011) } \\
{[16]}\end{array}$ & $\begin{array}{l}\text { Cross sectional } \\
\text { surveys pre/post } \\
\text { calorie menu label } \\
\text { implementation }\end{array}$ & $\begin{array}{l}\text { Calorie labels added to chain } \\
\text { restaurant labels in New York } \\
\text { City. Survey administered } \\
\text { outside fast food restaurants. }\end{array}$ & $\begin{array}{c}\text { New York City fast } \\
\text { food chains }\end{array}$ & $\begin{array}{c}7309 \text { adult } \\
\text { customers in } 2007 \\
\text { and } 8489 \text { in } 2009 \text {, } \\
168 \text { locations of } \\
11 \text { fast food } \\
\text { chains }\end{array}$ & $\begin{array}{l}\text { No change in mean calories } \\
\text { purchased overall chains from } \\
2007 \text { to } 2009,828 \vee 846 \mathrm{kcal}(\mathrm{p} \\
=0.22) \text {. Three chains show } \\
\text { reduction in mean calories per } \\
\text { purchase: McDonalds ( } 829 \vee 786 \\
\mathrm{p}<0.02), \text { Au Bon Pain }(555 \mathrm{v} \\
475, \mathrm{p}<0.001), \mathrm{KFC}(927 \vee 882 \\
\text { kcal, } p<0.001) \text {. One chain } \\
\text { significant increase: Subway (749 } \\
\vee 882, p<0.001) \text {. }\end{array}$ \\
\hline \multicolumn{6}{|l|}{$\begin{array}{c}\text { Laboratory } \\
\text { setting }\end{array}$} \\
\hline $\begin{array}{l}\text { Harnack et al. } \\
\text { (2008) [20] }\end{array}$ & $\begin{array}{l}\text { Non-blinded } \\
\text { randomized } \\
\text { controlled trial }\end{array}$ & $\begin{array}{l}\text { Order from } 4 \text { menu labeling } \\
\text { conditions, control that lists } \\
\text { items with standard pricing, } \\
\text { Item + Calorie menu, Item + } \\
\text { Non-value menu pricing, Calorie } \\
+ \text { Non-Value menu pricing. } \\
\text { Measured calories ordered and } \\
\text { calories consumed }\end{array}$ & $\begin{array}{l}\text { Conference room of } \\
\text { suburban hotel and } \\
\text { church basement in } \\
\text { Minneapolis St. Paul, } \\
\text { MN }\end{array}$ & $\begin{array}{c}594 \text { adolescents } \\
\text { and adults } 16 \text { or } \\
\text { older }\end{array}$ & $\begin{array}{l}\text { Mean calories ordered: Calorie } \\
\text { 873.6, Price 881.7, Calorie+Price } \\
\text { 842.3, Control 827.5 }(p=0.62) ; \\
\text { Mean calories consumed: Calorie } \\
\text { 804.7 Price 813.3 Calorie+Price } \\
\text { 761.0 Control } 739.0(p=0.25)\end{array}$ \\
\hline $\begin{array}{l}\text { Roberto et al. } \\
\text { (2010) [21] }\end{array}$ & $\begin{array}{l}\text { Non-blinded } \\
\text { randomized } \\
\text { controlled trial }\end{array}$ & $\begin{array}{l}\text { Participants order from } 3 \text { menu } \\
\text { labeling conditions, one that lists } \\
\text { the items, one that lists items } \\
\text { and calories, one that lists items, } \\
\text { calories and daily guideline } \\
\text { calories. Measured calories } \\
\text { ordered and calories consumed }\end{array}$ & $\begin{array}{c}\text { Laboratory in New } \\
\text { Haven, CT }\end{array}$ & $\begin{array}{c}303 \text { adults } 18 \text { and } \\
\text { older }\end{array}$ & $\begin{array}{c}\text { Mean calories ordered: Control } \\
2189 \text {, label condition } 1862(p= \\
0.03) \text {, label + info condition } \\
(1860, p=0.03) \text {, no significant } \\
\text { difference between two label } \\
\text { conditions. No significant } \\
\text { difference in calories consumed } \\
\text { overall }(p=0.12) \text {. }\end{array}$ \\
\hline
\end{tabular}


Table 2 Quality assessment of included studies

\begin{tabular}{|c|c|c|c|c|c|c|c|}
\hline Reference & $\begin{array}{l}\text { Study } \\
\text { design* }\end{array}$ & Randomization & Blinding & $\begin{array}{l}\text { Selection } \\
\text { bias }\end{array}$ & $\begin{array}{l}\text { Measurement } \\
\text { bias }\end{array}$ & Confounding & $\begin{array}{c}\text { Overall quality based on score } \\
\text { average** }\end{array}$ \\
\hline \multicolumn{8}{|c|}{ Real world settings } \\
\hline Elbel et al. (2011) [17] & 1 & NA & 0 & 1 & 2 & 0 & Fair \\
\hline Elbel et al. (2009) [18] & 1 & NA & 0 & 1 & 2 & 0 & Fair \\
\hline $\begin{array}{c}\text { Finkelstein et al. (2011) } \\
\text { [19] }\end{array}$ & 1 & NA & 2 & 2 & 2 & 1 & Good \\
\hline Chu et al. (2009) [6] & 0 & NA & 2 & 2 & 2 & 1 & Fair \\
\hline $\begin{array}{l}\text { Dumanovsky et al. } \\
\text { (2011) [16] }\end{array}$ & 0 & NA & 0 & 1 & 2 & 0 & Fair \\
\hline \multicolumn{8}{|c|}{ Laboratory settings } \\
\hline $\begin{array}{l}\text { Harnack et al. (2008) } \\
\text { [20] }\end{array}$ & 2 & 2 & 1 & 2 & 2 & 1 & Good \\
\hline $\begin{array}{l}\text { Roberto et al. (2010) } \\
\text { [21] }\end{array}$ & 2 & 2 & 0 & 2 & 2 & 1 & Fair \\
\hline
\end{tabular}

NA, not applicable

* Study design: Randomized controlled trials received a score of 2, cohort studies with comparison groups received a score of 1 , and single group studies (with no comparison group) received a score of 0

${ }^{* *}$ Quality scoring: 2 for good (or low potential for bias), 1 for fair (or moderate potential for bias), 0 for poor (or high potential for bias). To achieve a final quality rating of good, studies had to have an average score greater than or equal to 1.5 and could not receive scores of 0 for any individual variable. An average score less than or equal to 0.5 would have been considered to be a study with poor quality. Scores in between were considered fair quality studies.

difference between the no label menus and the calorie + information menus (1860 calories, $\mathrm{p}=0.03$ ). The difference between the calorie menus and calorie + information menus was not statistically significant $(\mathrm{p}=0.99)$. It is not clear why the difference in calories ordered between the groups appears to be more clinically significant than those noted in other studies [21]. However, the average number of calories ordered was also high compared to previous studies, which may account for some of this difference.

The effect of calorie menu labels on calorie consumption As noted above, two studies measured calories consumed in addition to calories ordered or calories purchased $[20,21]$. The distinction is an important one since consumers might theoretically respond to calorie posting on menus by changing the amount they eat rather than the amount they order. Harnack et al. found, however, that participants overall did not differ significantly in the number of calories they consumed by menu type (no label 739 , calorie labels 805 , no value pricing 761 calories, $\mathrm{p}=0.25$ )[20]. Subgroup analysis did demonstrate a difference in calories consumed. Men in groups with menus listing calorie information and those without value pricing consumed more calories than those with control menus $(\mathrm{p}=0.01)[20]$.

Roberto et al. also found no significant difference between calorie consumption when they examined consumption by menu type overall (no label 1459 vs. calorie label 1335 vs. calorie + information 1256, $\mathrm{p}=0.12$ )[21]. However, when they combined the two calorie label menus and compared them to the no label menu, they did find those in the labeled condition consumed fewer calories than those in the no label condition (label 1286 vs. no label $1466, \mathrm{p}=0.04)$ [21]. The credibility of this result is questionable considering the exploratory circumstances in which it was found. The average number of calories consumed was very high for a single meal.

\section{Sales volume}

Two studies reported measures of sales volume, neither of which found a significant difference in sales volume between periods with and without calorie posting $[6,19]$. Finkelstein et al. found no significant differences in the rate of ordering healthy or unhealthy menu items before and after calorie posting [19]. Chu et al. reported a significant decrease in the sale of entrées with the highest energy content during the treatment period (slope = -0.766 entrees/day, $p=0.007$ ) and an increase in sale of entrées with the highest energy content after the treatment period (slope $=1.541$ entrees/day, $\mathrm{p}=0.005$ )[6].

\section{Discussion}

Overall, the studies included in this review suggest that in both real world and experimental settings, calorie menu labeling has no effect or only a modest effect on calorie ordering and consumption. These results do not provide strong support for arguments that national expansion of calorie menu labeling will reduce rates of overweight and obesity. This evidence update supports the findings of the previous review from 2008 [5]. However, we should consider limitations of the current evidence as well as other important caveats before judging these policies. 


\section{Strengths and limitations of current evidence}

As noted above each study included in this review had methodological limitations. Finkelstein et al. provides the best evidence regarding implementation of calorie menu labeling in a real world setting and was the study with the highest quality overall included in this review. The researchers analyzed complete sales data furnished by a chain of restaurants in and surrounding King County, WA in a 13-month period during which the county implemented a calorie menu labeling requirement. The study provided more compelling data than three studies conducted in New York City, largely because researchers were able to track total monthly transactions and had complete sales data. In New York City, although researchers gathered data from multiple restaurants, they had no measure of overall volume of sales. This is important because one possible effect of calorie menu labeling is that consumers choose not to patronize restaurants where unhealthy choices dominate.

With the observational studies it is entirely possible that confounding factors were responsible for the reported effects of calorie labeling. In New York City and King County, WA, researchers did not measure consumption patterns which could have changed with calorie labeling even if ordering patterns remained constant. Moreover, none of the observational studies could account for environmental factors, such as public education campaigns accompanying the policy implementation, which might have contributed to behavior change over the course of the study. Since four of five studies showed that calorie labels did not lead to decreased calorie ordering, we can feel comfortable that results are not skewed toward a positive result.

Although randomized trials are considered stronger designs because they have the potential to minimize confounding and selection bias, the two trials included in this review cannot easily be generalized to real world behavior and do not necessarily provide more compelling data than the observational research. Regardless of efforts to improve real world applicability or conceal study aims, participants are likely to order and eat differently when they are being monitored and eating in groups. Moreover, in the real world, people have the choice to forgo quick-service restaurant meals in favor of those prepared at home (though we are doing so less frequently as a nation) $[4,15]$.

The two experimental studies included in this review reported conflicting results on calorie ordering and consumption, which could be a product of study design, demographic variables, label design or measurement. Participants in the Roberto et al. research [21], which demonstrated the largest effect from calorie labeling, ordered over twice as many calories and consumed several hundred more calories than those in any other study [21]. The authors offer no explanation for the increased caloric consumption, but it is possible that ordering and eating habits deviated from the norm due to the nature of the eating environment.

\section{Directions for future research}

Current research on calorie menu labeling suffers from two basic deficiencies. Observational studies are insufficient for drawing causal inferences and experimental studies conducted in laboratory settings cannot simulate real world behavior, particularly when repeated exposure to menu labels may be required to influence choice $[5,14,15,20]$. With industry and governmental participation, large scale randomized trials could be conducted by gradually staging calorie menu label implementation on a state or county level in a randomized fashion. Researchers could then monitor ordering patterns, sales volume and even trends in overweight and obesity during parallel time periods in areas with and without labeling [15]. These large trials would provide the strongest evidence were researchers able to measure the number of calories consumed, not just the number ordered, as some consumers may respond to calorie labeling by changing their eating and not their ordering habits. However, both funding and lack of industry cooperation would likely constitute significant barriers to this sort of research $[19,20]$.

Several of the studies in this review indicated that not all consumers or participants were aware of calorie labels $[17,18,20]$. Accompanying labels with educational materials to increase awareness and explain their use improves effects on food choice [5]. Future research should examine whether such efforts could also improve efficacy of calorie menu labeling. Researchers should also consider whether health and lifestyle variables-dieters vs. non-dieters, for example-affect how labeling influences choice.

In addition to how calorie labels affect consumers, future research should focus on the behavior of the food service industry. None of the studies monitored industry response to calorie menu labeling, including altering menus to improve nutrition profiles of current offerings or add healthier items. Unfortunately, because of low health literacy, lack of understanding of nutrition labels and misestimation of nutritional content in restaurant meals $[4,14]$, consumers may also be susceptible to deliberate or inadvertent manipulation by the restaurant industry. Stated caloric estimates may also be incorrect [22]. As menu labeling becomes more prominent nationally, policy makers and industry regulators must be attentive to the truthfulness and clarity of new labels. Future research should also explore understanding of various label formats to make sure that responses correspond to intended meaning. 


\section{Limitations of the current review}

This review was limited in scope, in particular by restricting eligibility to studies published after 2006. In their previous review, Harnack and French concluded that calorie labeling might have a small effect on choice behavior [5]. The search also did not include other sources of peer reviewed or grey literature (a recent issue brief sites several unpublished studies of calorie menu labels)[15]. Finally, several excluded studies published since 2006 measure behavioral intent using calorie menu labels. That literature may provide an additional perspective on the potential for calorie menu labels to influence food choices.

\section{Conclusion}

From the evidence included in this review, it appears that calorie menu labeling does not have the intended effect of decreasing calorie ordering and consumption from quick-service restaurants. We also need longerterm, scientifically rigorous studies to determine whether prolonged exposure to calorie labels has an effect on rates of overweight or obesity, the health outcome of interest [15].

In the meantime, we must proceed with caution in widespread implementation of an unproven policy with social and monetary costs, especially since the effort may detract attention from other effective strategies to combat overweight and obesity or have inadvertent effects [15]. Given that a majority of US consumers indicate that they want calorie menu labeling [14,23], and the policy now seems imminent, knowledge of successful strategies as well as potential negative ramifications should be carefully considered when deciding how the policy will be operationalized and implemented.

\section{Acknowledgements}

The authors wish to thank Alice Ammerman, DrPH, for her review of an earlier version of this manuscript. The University of North Carolina at Chapel Hill's Libraries provided support for open access publication. A grant from the University Research Council at the University of North Carolina at Chapel Hill also supported this open access publication.

\section{Author details \\ 'Public Health Leadership Program, Gillings School of Global Public Health, University of North Carolina at Chapel Hill, Chapel Hill, NC, USA. ${ }^{2}$ Nutrition Department, Gillings School of Global Public Health, University of North Carolina at Chapel Hill, Chapel Hill, NC, USA. ${ }^{3}$ Department of Family Medicine, University of North Carolina at Chapel Hill School of Medicine, Chapel Hill, NC, USA.}

\section{Authors' contributions}

JS conducted the literature search, reviewed each of the studies and drafted the manuscript. AV reviewed the studies and made contributions to multiple revisions of the manuscript. DB provided guidance about the content of the review, suggested pertinent literature, and contributed to multiple revisions of the manuscript. All authors read and approved the final manuscript.

Authors' information

Contact information:
Danielle Braxton, MPH RD LDN

UNC Gillings School of Global Public Health

2200 McGavran-Greenberg Hall, CB \#7461

Chapel Hill, NC 27599-7461

furci@unc.edu

Anthony J. Viera, MD MPH

UNC-Chapel Hill, DOFM

CB\# 7595, 590 Manning Dr.

Chapel Hill, NC 27599-7595

anthony_viera@med.unc.edu

\section{Competing interests}

The authors declare that they have no competing interests.

Received: 29 August 2011 Accepted: 8 December 2011

Published: 8 December 2011

\section{References}

1. Nestle M: Health care reform in action-calorie labeling goes national. $N$ Engl J Med 2010, 362:2343-2345.

2. Mokdad AH, Serdula MK, Dietz WH, Bowman BA, Marks JS, Koplan JP: The spread of the obesity epidemic in the United States, 1991-1998. JAMA 1999, 282:1519.

3. Mokdad AH, Serdula MK, Dietz WH, Bowman BA, Marks JS, Koplan JP: The continuing epidemic of obesity in the United States. JAMA 2000, 284:1650.

4. Variyam JN: Nutrition labeling in the food-away-from-home sector: an economic assessment. Economic Research Report Number 42005 [http:// www.ers.usda.gov/Publications/ERR4/], Accessed November 25, 2011.

5. Harnack $\sqcup$, French SA: Effect of point-of-purchase calorie labeling on restaurant and cafeteria food choices: A review of the literature. Int J Behav Nutr Phys Act 2008, 5:51.

6. Chu YH, Frongillo EA, Jones SJ, Kaye GL: Improving patrons' meal selections through the use of point-of-selection nutrition labels. Am J Public Health 2009, 99:2001-2005.

7. Berman M, Lavizzo-Mourey R: Obesity prevention in the information age: caloric information at the point of purchase. JAMA 2008, 300:433-435.

8. Jeffery RW, Baxter J, McGuire M, Linde J: Are fast food restaurants an environmental risk factor for obesity? Int J Behav Nutr Phys Act 2006, 3:2.

9. Pereira MA, Kartashov Al, Ebbeling CB, Van Horn L, Slattery ML, Jacobs DR: Fast-food habits, weight gain, and insulin resistance (the CARDIA study): 15-year prospective analysis. The Lancet 2005, 365:36-42.

10. Patient Protection and Affordable Care Act of 2010. HR3590, 111th Cong 2010, 148(111):1001-10909.

11. Blumenthal K, Volpp KG: Enhancing the Effectiveness of Food Labeling in Restaurants. JAMA 2010, 303:553.

12. Dumanovsky T, Huang CY, Bassett MT, Silver LD: Consumer Awareness of Fast-Food Calorie Information in New York City After Implementation of a Menu Labeling Regulation. Am J Public Health 2010, 100:2520.

13. Fitch RC, Harnack $L$, Neumark-Sztainer DR, Story MT, French SA, Oakes JM, Rydell SA: Providing calorie information on fast-food restaurant menu boards: consumer views. Am J Health Promot 2009, 24:119-132.

14. Larson N, Story M: Menu Labeling: Does Providing Nutrition Information at the Point of Purchase Affect Consumer Behavior. Robert Wood Johnson Foundation 2009 [http://http://www.rwjf.org/files/research/ 20090630hermenulabeling.pdf], Accessed Nov. 25, 2011.

15. Allison D: Evidence, discourse and values in obesity-oriented policy: menu labeling as a conversation starter. Int J Obes 2011, 35:464-471.

16. Dumanovsky T, Huang CY, Nonas CA, Matte TD, Bassett MT, Silver LD: Consumer Awareness of Fast-Food Calorie Information in New York City After Implementation of a Menu Labeling Regulation. BMJ 2011, 343: d4464.

17. Elbel B, Gyamfi J, Kersh R: Child and adolescent fast-food choice and the influence of calorie labeling: a natural experiment. Int J Obes 2011, 35:493-500.

18. Elbel B, Kersh R, Brescoll VL, Dixon LB: Calorie labeling and food choices: a first look at the effects on low-income people in New York City. Health Aff (Millwood) 2009, 28:w1110-21.

19. Finkelstein $\mathrm{EA}$, Strombotne $\mathrm{KL}$, Chan $\mathrm{NL}$, Krieger J: Mandatory menu labeling in one fast-food chain in King County, Washington. Am J Prev Med 2011, 40:122-127. 
20. Harnack LJ, French SA, Oakes JM, Story MT, Jeffery RW, Rydell SA: Effects of calorie labeling and value size pricing on fast food meal choices: results from an experimental trial. Int J Behav Nutr Phys Act 2008, 5:63.

21. Roberto CA, Larsen PD, Agnew H, Baik J, Brownell KD: Evaluating the impact of menu labeling on food choices and intake. Am J Public Health 2010, 100:312-318.

22. Urban LE, McCrory MA, Dallal GE, Das SK, Saltzman E, Weber JL, Roberts SB: Accuracy of stated energy contents of restaurant foods. JAMA 2011 306:287.

23. Bleich SN, Pollack KM: The publics' understanding of daily caloric recommendations and their perceptions of calorie posting in chain restaurants. BMC Public Health 2010, 10:121.

doi:10.1186/1479-5868-8-135

Cite this article as: Swartz et al: Calorie menu labeling on quick-service restaurant menus: an updated systematic review of the literature. International Journal of Behavioral Nutrition and Physical Activity 2011 8:135.

\section{Submit your next manuscript to BioMed Central} and take full advantage of:

- Convenient online submission

- Thorough peer review

- No space constraints or color figure charges

- Immediate publication on acceptance

- Inclusion in PubMed, CAS, Scopus and Google Scholar

- Research which is freely available for redistribution

Submit your manuscript at www.biomedcentral.com/submit 